\title{
Comparing the English Video Lineup with the 48-Person Lineup
}

\author{
Avraham Levi
}

On Pension from the Israeli Police, Israel

Copyright $@ 2017$ by authors, all rights reserved. Authors agree that this article remains permanently open access under the terms of the Creative Commons Attribution License 4.0 International License

\begin{abstract}
Levi has been experimenting with large lineups, in particular a 48-person lineup. After showing experimental participants a 2 minute video more than an hour before, participants were shown 4 screens of 12 lineup members. They could view the screens as often as they liked before reaching a decision. This study compared the 48-person lineup with the British lineup. Contrary to prediction, the British lineup did not outperform the 48-person one in identifications of the target. As there was also no difference in mistaken choices in target-absent lineups, as expected the 48-person lineup outperformed the British lineup, since the likelihood that the innocent suspect would be the person chosen is $1 / 10$ in the ten-person British lineup, while only 1/48 in the 48-person lineup.
\end{abstract}

Keywords 48-Person Lineups, The British Lineup, Identifications, Mistaken Identifications, Eyewitness Identification

\section{Introduction}

The lineup is a procedure in which a person suspected by the police of having committed a crime is shown the witness, along with a number of known innocent people ("foils"). If a witness chooses the suspect, this is taken as evidence of his guilt by the courts. Photos are often used today in place of the actual people (a live lineup). The most common lineup is the simultaneous lineup, in which the witness views all the lineup members simultaneously. A fair lineup is one in which each of the foils and the innocent or guilty suspect have an equal chance of being chosen by people who have never seen the suspect ["mock witnesses", Doob \& Kirshenbaum [1], who have been given a description of the target]. The lineup is the safest eyewitness identification procedure, because the foils provide some protection to an innocent suspect. However, it is far from perfect. There is ample evidence that witnesses often choose someone who is not the culprit (Conners et al. [2]; Scheck, Neufeld, \& Dwyer, [3], Valentine, Pickering, \& Darling [4]; Wells et al. [5]). When they choose someone who is not the suspect but a known innocent, the police know that they have erred. However, in a fair simultaneous lineup by chance these witnesses who choose will "identify" a suspect who is innocent $1 / \mathrm{N}$ times, where $\mathrm{N}$ is the lineup size. With the common American lineup size of six, this will happen $1 / 6=0.167$, or almost $17 \%$ of the time. This is much too great an error.

There is a second error that witnesses often make which goes undetected by the police: witnesses fail to identify guilty suspects (Levi [6]). While a number of innovative lineup procedures have been developed to reduce mistaken identifications (Levi [7]; Levi [8]; Lindsay \& Wells [9]; Pryke et al. [10]), there have been few procedures available to increase correct ones that do not simultaneously increase mistaken ones.

Lindsay and Wells (1985 [11]), for example, introduced the sequential lineup. In that lineup witnesses view the lineup members one at a time, only once, and the lineup ends when the witness chooses someone. However, while this lineup does indeed decrease mistaken identifications, the cost is actually some decrease in correct ones (Steblay, Dysart \& Wells [12]). With only 36\% choices when the target is absent the innocent suspect will be chosen $36 / 6=6 \%$ of the time in the six-person American lineup. This remains too large a danger for an innocent suspect (Dupuis \& Lindsay, 2007 [13]).

The reason that finding procedures to increase correct identifications has been so difficult is because that goal usually conflicts with the desire to reduce mistaken ones. Witnesses often have imperfect memory (Buckhout [14]) and can then often only increase correct identifications if they choose someone in the lineup more often. Doing this is precisely what increases mistaken ones.

The danger of mistaken identifications has been considered so great that in the wake of research showing that we can reduce them if we warn witnesses that the 
culprit may not be in the lineup (Malpass \& Devine [15]), the warning has been included in one of four recommendations of a White Paper of the American Psychological Association (Wells et al., 1998 [16]) to improve lineup identification evidence.

There is clearly a need for a new lineup which reduces mistaken identifications much more than any presently being used, without causing as much a reduction in correct ones. Levi and Lindsay, (2001 [17]) proposed exploring large lineups, that could reduce false identifications if the rate by which witnesses chose someone in target-absent lineups increased less than the increased lineup size. Thus, if a 40-person lineup had the same rate of mistaken choices as the six-person lineup, the number of false identifications would be $57 / 40=1.04 \%$. This is clearly a tremendous improvement.

Levi (2006b [18], 2007 [19], 2012 [20]) has been experimenting with very large lineups, the largest consisting of 120 members. Each lineup consists of 12 photos per screen, such that a 48-person lineup has four screens, a 120-person lineup having ten. The two consistent findings have been that both the number of correct identifications and the amount of choosing when the target is absent (mistaken choices) remain constant and comparable to small lineups even as the lineup grows from 24 to 120 members. The result has been a dramatic reduction in mistaken identifications at no cost to correct ones. For example, with a typical rate of $50 \%$ mistaken choices in the traditional six-person target -absent simultaneous lineup, if the lineup is fair the expected rate of mistaken identifications is $50 / 6=8.3 \%$. With a relatively small large lineup of 48 , the same percentage of mistaken choices leads to $50 / 48=1 \%$ mistaken identifications. This rate is also much better than achieved with the sequential lineup.

In a further experiment Levi ([21]) posited another advantage of large lineups. He suggested the possibility that in small simultaneous lineups witnesses were able to use partial memory of the target to discount some of the lineup members. Then, simply by guessing between the remaining ones, they increased their chances greatly of picking the target. He noted that this would not be a true identification of the target, only an educated guess. On the other hand, in a large lineup, even after discounting some lineup members many more would be left. An educated guess would still be between a fairly large numbers of lineup members. Thus, when witnesses chose the target, there would be a far greater chance that they actually had identified him than in a small lineup.

Levi ([22]) asked witnesses who viewed either a six-person or 48-person lineup to count the number of lineup members that they could discount, and found indeed that the remaining ones were a lot less in the six-person lineup. Levi then tentatively concluded that an additional advantage of the 48-person lineup was that we could be a lot more certain that when the target was picked the witness truly identified him, and had not made an educated guess.

A popular rival theory explaining why witnesses choose the target more often in simultaneous lineups than in sequential lineups is the notion of relative judgment (Lindsay \& Wells, 1985 [23]). According to this idea witnesses with imperfect memory compare between the lineup members and pick the person who seems most similar to their memory of the target.

The British lineup is unique. Rather than taking photographs of suspects, the police take short video-clips of them. Each person looks straight at the camera, turns his head to one side, then the other, before returning to look straight at the camera. For the lineup, they choose nine appropriate video-clips to show along with the suspect. The video-clips are shown one at a time, and then they are shown a second time, before the witness makes a decision.

Perhaps there were less identifications in the 48-person lineup because finding the target among 48 photos is a more difficult task than finding him among six. The present study gives an opportunity of testing this theory. The British lineup differs from the six-person simultaneous one in that the photos are shown sequentially. This gives witnesses a far less opportunity to compare between the lineup members and to hit upon the strategy to discount some and guess from the remaining ones. Thus, even though the British lineup consists of only 10 members, we may not find the large advantage in identifications over the 48-person that we have found with the six-person simultaneous one.

Another reason for conducting the present experiment is simply to prove the superiority of 48-person lineups, so far not used by any police force, over the British lineup almost always used today in Great Britain.

We have reason to believe that this lineup is inferior to the 48-person lineup because it is a lot smaller. If witnesses choose and the suspect is innocent, they have a one out ten chance of mistakenly choosing him. This compares to a one out of 48 chance of choosing him in the 48-person lineup.

This will be true if, as we have found so with the simultaneous lineup, there is no tendency to choose more often in target-absent lineups. On the other hand, there is a possibility that witnesses will choose the target more. Often in the British lineup, just as they do in the six-person simultaneous lineup.

This experiment tests these predictions. High confidence might enable us to differentiate some of the British lineup "identifications" as true ones, and therefore witnesses were asked after every choice of a lineup member to state how confident they were in that choice. Finally, all witnesses were asked to count the number of lineup members that they could discount.

\section{Method}

Participants: The participants were staff and graduate 
students at Tel Aviv University, Tel Aviv ${ }^{1}$, Israel, who agreed to participate in an interesting experiment which would require them to watch a two- minute video immediately and at least an hour later participate in the five minute experiment which would take place in their office/lab. Of the 208 participants, 83 were male, 125 females. The average age of the participants was 33 .

Design: The design was two $\mathrm{x}$ two between-subjects, the independent variables being lineup type (48-person, British lineup) and presence of target (present, absent). The dependent variables were lineup decision, confidence, and number of lineup members that could be discounted. Participants were randomly assigned to each of the four independent conditions, so that they did not differ in age, sex or status in the university. There were 52 participants in each condition.

Recruitment and eyewitness event: The author visited offices and labs at the university. He introduced himself, and asked the occupants whether they would participate in an interesting experiment in their office/lab that involved viewing a 2- minute video immediately, and participating at a later time in the experiment that would last about five minutes. If a person agreed, he showed the video in their office in which the target was seen for 37 seconds, another young-looking male for 22 seconds $^{2}$. Two women also appeared in the lineup, along with a baby who was being diapered. He arranged a mutual acceptable time for the experiment, at least an hour later. The video and the lineup were shown on a laptop computer.

The lineups: Ten video-clips for the British lineup were taken of students near the entrance of the Mt Scopus campus of the Hebrew University of Jerusalem, Israel, following the British method of each person looking straight at the camera, moving his head to one side, then the other, before returning to look straight at the camera. A similar video-clip of the target was taken.

The photos for the 48-person lineup were chosen from Levi (2012 [24]), and photos of the students whose video-clips were taken. The 48 photos were organized in four screens of 12 photos each, in two lines of six. For the screen in which the target appeared, he was placed in the lower line in the fifth place. For the target-absent condition, an additional photo was chosen at random to replace the target.

All lineup members were young adult males who had

\footnotetext{
${ }^{1}$ This sample was chosen for sake of convenience. While it in known that young adults have superior eyewitness memory, the same sample was used for all experimental conditions, and therefore age is controlled for. ${ }^{2}$ The video was a natural domestic scene showing a mother diapering her baby in the baby's room, a young-looking male and an older woman sitting in the living room, and the target moving into the living room, sitting down, putting on his shoes, and moving in and out of the room where the mother was diapering the baby. The video can be viewed at www.youtube.com/watch?v=wmbBujTSngo or can be obtained from the author.
}

dark and short hair, dark eyes, no beard or moustache, and were of medium build. The target also fit this description. The photos and videos were thus chosen to fit the match-to-description criterion (Wells et al., 1998 [25]), and there is thus no danger that any of them could be discounted because they did not fit that description.

Procedure: Witnesses were told: "I am now going to conduct a lineup. You are to find the person who moved from one room to another in the video-clip. He may not be in the lineup". Witnesses shown the British lineup was then told: "I will now show videos of ten people one after the other, twice" Witnesses shown the 48-person lineup were told: "I will show you four screens of photos. You can go back and see previous screens".

Witness who chose someone was asked to give their confidence in their decision, as a percentage. Finally, all witnesses were asked to count the number of lineup members that they could discount.

\section{Results}

Table 1 summarizes the lineup decision of each witness for the four experimental conditions. The difference in number of identifications between the 48-person lineup and the British lineup is not statistically significant $(\mathrm{z}=$ 0.066 , test for the difference between two proportions). The chance of mistakenly choosing an innocent suspect is mistaken choices divided by $\mathrm{N}$, where $\mathrm{N}$ is lineup size. Thus, in the 48-person lineup this was 34 mistaken choices $/ 48=0.708$, while in the British lineup it was 30/10 $=3$.

Table 1. Results for four experimental conditions

\begin{tabular}{|c|c|c|}
\hline Target-present & 48-person lineup & English lineup \\
\hline Identification & $10(19 \%)$ & $15(29 \%)$ \\
\hline Foil & $29(56 \%)$ & $24(46 \%)$ \\
\hline No choice & $13(25 \%)$ & $13(25 \%$ \\
\hline Target-absent & & $30(58 \%)$ \\
\hline Mistaken choice & $34(66 \%)$ & $22(42 \%)$ \\
\hline No choice & $18(35 \%)$ & \\
\hline
\end{tabular}

The average number of lineup members left after discounting some in the 48-person lineup was 9.098, while for the English lineup the number left was 2.96. The difference between these means, is significant, $z=7.809$ $\mathrm{p}<0.000003$.

On the other hand, confidence judgments proved to be an unreliable indicator of accuracy. For each level of confidence of $50 \%$ and above, there were more incorrect judgments than correct ones.

\section{Discussion}

This experiment compared the performance of the 
48-person lineup to the British video lineup. It was predicted that, as with the six-person lineup (Levi [26]), the British lineup would outperform the 48-person lineup in rate of identifications. On the other hand, the 48-person lineup would be vastly superior to the English lineup in preventing mistaken identifications. Further, it was predicted that after discounting foils the 48-person lineup would be left with far more lineup members to choose from.

All but the first prediction was verified. There was not a significant difference in the rate of identifications between the two lineups. However, due to the far smaller English lineup of ten, the chance of mistakenly identifying an innocent suspect was more than three times greater. Also, more than three times as many foils were left for witnesses to choose from in the 48-person lineup after discounting those that the witness was sure could not be the target. Confidence was not found to improve the ability to distinguish between an accurate and an accurate decision in either lineup.

The basic conclusions are that, with no difference in the rate of identifications but a far less chance of mistaken identifications, the 48-person lineup is superior to the English video lineup. Furthermore, despite the fact that the 48-person lineup was far larger, it produced the same number of identifications. This argues against the fear that witnesses get confused with this lineup. This fits Levi's (2012 [27] finding of no difference in the number of identifications between a 24-person lineup and larger ones.

Levi ([27]) argued that witnesses viewing six-person lineups use partial memory of the target to discount many lineup members. This allows them, if they guess from among the remaining members, to increase the likelihood that they will pick the target. In this experiment, as in Levi ([28]), witnesses in the far smaller British lineup were left with far fewer lineup members after they discounted ones in the smaller lineup than in the 48-person one. Despite this fact, witnesses viewing the British lineup did not use it to discount lineup members while viewing the lineup. However, witnesses were asked to count how many members they could discount after they had made their lineup decision.

The method of discounting some members and guessing from amongst the remaining ones is likely a conscious strategy. It may very well be that the strategy did not occur to the British lineup witnesses. This may contrast with six-person lineup witnesses. One may posit that the six-person simultaneous lineup encourages witnesses much more to compare between the lineup members, and note that the discounting strategy is effective, than the sequential presentation of the British lineup. This hypothesis can be tested by running an experiment in which British lineup witnesses are asked to discount members before they make their lineup decision.

This hypothesis dovetails with Levi's (2012, [30]) discovery of a subsample of witnesses who did better with a twelve-person simultaneous lineup (one screen) than with larger lineups. It seems that some witnesses were smart enough to hit upon the discounting strategy when faced with the twelve-person lineup.

The superiority of the 48-person lineup over the English video lineup poses a problem for the English police. By law they are forbidden to conduct photo lineups, and the law cannot be easily changed. An interesting alternative would be to have all the photos in each of the four screens of the 48-person lineup are a video-clip, following the English lineup format. On the face of it such an option's only purpose would be to circumvent the English law. However, we can never be sure until it is tried.

\section{REFERENCES}

[1] Doob, A. N., \& Kirshenbaum, H. M. (1973). Bias in police lineups-partial remembering. Journal of Police Science and Administration, 1, 287-293.

[2] Conners, E, Lundregan, T, Miller, N, McEwen, T. (1996) Convicted by juries, exonerated by science: Case studies in the use of DNA evidence to establish innocence after trial. Washington: U. S. Department of Justice, 1996 trial. Washington: U. S. Department of Justice, 1996.

[3] Scheck, B., Neufeld, P., \& Dwyer, J. (2001). Actual innocence: When justice goes wrong and how to make it right. New York: Signet.

[4] Valentine, T., Pickering, A., \& Darling, S. (2003). Characteristics of eyewitness identification that predict the outcome of real lineups. Applied Cognitive Psychology, 17, 969-993.

[5] Wells, G. L., Small, M., Penrod, S., Malpass, R. S., Fulero, S. M., \& Brimacombe, C.A. E. (1998). Eyewitness identification procedures: Recommendations for lineups and photospreads. Law and Human Behavior, 22, 603-647.

[6] Levi, A. M. (1998). Are defendants guilty if they were chosen in a lineup? Law and Human Behavior, 22, 389-407.

[7] Levi, A. M. (2006a). An Analysis of Multiple Choices in MSL Lineups, and a Comparison with Simultaneous and Sequential ones. Psychology, Crime, \& Law, 12, 273-285.

[8] Levi, A. M. (2012). Much Better than the Sequential lineup: A 120-person lineup. Psychology, Crime \& Law, 18, 631-640.

[9] Lindsay, R. C. L., \& Wells, G. (1985). Improving eyewitness identifications from lineups: Simultaneous versus sequential lineup presentation. Journal of Applied Psychology, 70, 556-564.

[10] Pryke, S., Lindsay, R. C. L., Dysart, J. E., \& Dupuis, P. (2004). Multiple independent identification decisions: A method of calibrating eyewitness identifications. Journal of Applied Psychology, 89, 73-84.

[11] Dupuis P. R., \& Lindsay, R. C. L. (2007). Radical alternatives traditional lineups. In R. Lindsay, R. Ross, D. Read, \& M. Toglia (Eds Handbook of eyewitness 
psychology: Memory for people (Vol. 2, pp 179-200). Mahwah, NJ: Lawrence Erlbaum and Associates.

[12] Lindsay, R. C. L., \& Wells, G. (1985). Improving eyewitness identifications from lineups: Simultaneous versus sequential lineup presentation. Journal of Applied Psychology, 70, 556-564.

[13] Steblay, N. K., Dysart, J. E., \& Wells, G. L. (2011). Seventy-two tests of the sequential lineup superiority effect: A Meta-Analysis and Policy Discussion. Psychology, Public Policy, and Law, 17, 99-139.

[14] Buckhout, R. (1974). Eyewitness memory. Scientific American, 231, 23-31.

[15] Malpass, R. S., \& Devine, P. G. (1981). Eyewitness identification: Lineup instructions and the absence of the offender, Journal of Applied Psychology, 66, 482- 489.

[16] Wells, G. L., Small, M., Penrod, S., Malpass, R. S., Fulero, S M., \& Brimacombe, C.A. E. (1998). Eyewitness identification procedures: Recommendations for lineups and photospreads. Law and Human Behavior, 22, 603-647.

[17] Levi, A. M., \& Lindsay, R. C. L. (2001), Issues concerning policy recommendations: The example lineups and photospreads. Psychology, Public Policy, \& Law, 7, 776-790.

[18] Levi, A. M. (2006b). A Comparison Between Large Simultaneous and MSL Lineups, with Photos Viewed in Sets of Six. In K. Nixon (Ed.) Forensic recall and eyewitness testimony. (pp.91-101) London: IA-IP Publishing

[19] Levi, A. M. (2007). Evidence for Moving to an 84- Person
Photo Lineup Journal of Experimental Criminology, 3,377-391.

[20] Levi, A. M. (2012). Much better than the sequential lineup: a 120-person lineup Psychology, Crime \& Law, 18, 631-640.

[21] Levi, A. M. (under review, b). Partial memory: Another reason for using large lineups.

[22] Levi, A. M. (under review). Partial memory: Another reason for using large lineups.

[23] Lindsay, R. C. L., \& Wells, G. (1985). Improving eyewitness identifications from lineups: Simultaneous versus sequential lineup presentation. Journal of Applied Psychology, 70, 556-564.

[24] Levi, A. M. (2012). Much better than the sequential lineup: a 120-person lineup Psychology, Crime \& Law, 18, 631-640

[25] Wells, G. L., Small, M., Penrod, S., Malpass, R. S., Fulero, S. M., \& Brimacombe, C.A. E. (1998). Eyewitness identification procedures: Recommendations for lineups and photospreads. Law and Human Behavior, 22, 603-647.

[26] Levi (under review). Partial memory: Another reason for using large lineups. 27. Levi, A. M. (2012). Much better than the sequential lineup: a 120-person lineup Psychology, Crime \& Law, 18, 631-640

[27] Levi (under review). Partial memory: Another reason for using large lineups.

[28] Levi, A. M. (2012). Much Better than the Sequential lineup: A 120-person lineup. Psychology, Crime \& Law, 18, 631-640. 